\title{
Minat dan Kualitas Pelayanan Terhadap Tingkat Kunjungan ke Perpustakaan
}

\author{
Eti Sumiati \\ Institut Pemerintahan Dalam Negeri (IPDN) \\ esumiati70@gmail.com
}

\begin{abstract}
ABSTRAK
Penelitian ini bertujuan untuk mengetahui minat dan kualitas pelayanan terhadap tingkat kunjungan di perpustakaan IPDN Jatinangor. Hasil penelitian menunjukkan minat dan kualitas pelayanan berpengaruh secara parsial dan simultan terhadap tingkat kunjungan di perpustakaan IPDN Jatinangor. Dimana, variabel minat anggota dan kualitas pelayanan bersama-sama memiliki pengaruh sebesar 51,80\% terhadap tingkat kunjungan perpustakaan IPDN Jatinangor.
\end{abstract}

Kata Kunci : Tingkat Kunjungan, Perpustakaan.

\section{ABSTRACT}

This study aims to determine the interest and quality of service to visit level in the library IPDN Jatinangor. The result of the research shows that the interest and the quality of service have partial and simultaneous effect on visit level in the library of IPDN Jatinangor. Where, member interest variable and service quality together have influence equal to 51,80\% to visit level of library of IPDN Jatinangor.

Keywords: Visit Level, Library.

\section{PENDAHULUAN}

\section{Latar belakang Penelitian}

Menurut Undang-Undang RI Nomor 43 Tahun 2007 Tentang Perpustakaan pasal 1 ayat 1 menyatakan bahwa "Perpustakaan adalah institusi pengelola koleksi karya tulis, karya cetak, dan/atau karya rekam secara professional dengan sistem yang baku guna memenuhi kebutuhan pendidikan, penelitian, pelestarian, informasi, dan rekreasi para pemustaka".

Berdasarkan hasil pengolahan data sekunder di Perpustakaan IPDN Jatinangor, Jumlah praja di IPDN Jatinangor, jumlah anggota, jumlah anggota aktif, jumlah kunjungan perpustakaan per tahun di perpustakaan dan jumlah rata- rata kunjungan per bulan di perpustakaan IPDN Jatinangor berkembang secara fluktuatif. Hal ini dapat dilihat pada tabel 1.1 mengenai data yang telah diolah pada tahun 2011 sampai dengan tahun 2016 dengan data sebagai berikut :
Tabel 1.

Perkembangan Jumlah Praja, Jumlah Anggota Perpustakaan Yang Aktif, Jumlah Kunjungan per Tahun dan Jumlah Rata-Rata Kunjungan per Bulan Perpustakaan IPDN Jatinangor Tahun 2011 s.d. 2016

\begin{tabular}{ccccccc} 
N & Tahun & $\begin{array}{c}\text { Jumla } \\
\text { h } \\
\text { Praja }\end{array}$ & $\begin{array}{c}\text { Jumlah } \\
\text { Anggota }\end{array}$ & $\begin{array}{c}\text { Jumlah } \\
\text { Anggota } \\
\text { Aktif }\end{array}$ & $\begin{array}{c}\text { Jumlah } \\
\text { Kunjun } \\
\text { gan/ } \\
\text { Tahun }\end{array}$ & $\begin{array}{c}\text { Jumlah } \\
\text { Rata- } \\
\text { Rata } \\
\text { Kunju- } \\
\text { ngan } \\
\text { Per } \\
\text { Bulan }\end{array}$ \\
\hline 1 & 2011 & 3,465 & 3,125 & 2,219 & 15,502 & 1,292 \\
2 & 2012 & 4,449 & 3,200 & 2,464 & 16,697 & 1,391 \\
3 & 2013 & 9 & 3,617 & 2,065 & 15,453 & 1,288 \\
4 & 2014 & 3,400 & 3,226 & 1,935 & 21,261 & 1,772 \\
5 & 2015 & 3,722 & 2,559 & 1,800 & 17,342 & 1,445 \\
6 & 2016 & 3,771 & $\mathbf{3 , 4 4 1}$ & $\mathbf{2 , 9 1 0}$ & $\mathbf{2 8 , 0 9 2}$ & $\mathbf{2 , 3 4 1}$ \\
\hline Sumb & & & & & &
\end{tabular}

Dan untuk jumlah kunjungan anggota dalam setahun menunjukan jumlah yang fluktuatif di setiap tahunnya. Dan untuk lebih detailnya dapat dilihat pada tabel 1.2 mengenai presentase perkembangan jumlah praja, jumlah anggota perpustakaan, dan jumlah kunjungan rata-rata anggota perpustakaan per bulan. 
Tabel 2.

Perkembangan Jumlah Praja, Jumlah Anggota Perpustakaan Jumlah Rata-Rata Kunjungan per Bulan Perpustakaan IPDN Tahun 2012 s.d. 2016

\begin{tabular}{|c|c|c|c|c|c|}
\hline No & Tahun & $\begin{array}{l}\text { Jumlah } \\
\text { Praja \% }\end{array}$ & $\begin{array}{c}\text { Jumlah } \\
\text { Anggota } \\
\%\end{array}$ & $\begin{array}{c}\text { Jumlah } \\
\text { Anggota } \\
\text { Aktif } \\
\%\end{array}$ & $\begin{array}{c}\text { Persentasi Rata- } \\
\text { Rata Kunjungan } \\
\text { Per Bulan }\end{array}$ \\
\hline 1 & 2012 & 28,40 & 2.40 & 11.04 & 7.71 \\
\hline 2 & 2013 & 3.89 & 13.03 & (16.19) & $(7.45)$ \\
\hline 3 & 2014 & $\begin{array}{r}(30.46 \\
)\end{array}$ & (10.81) & $(6.30)$ & 37.58 \\
\hline 4 & 2015 & 9.47 & (20.68) & (6.98) & (18.43) \\
\hline 5 & 2016 & 1.32 & 34.47 & 61.67 & 61.99 \\
\hline
\end{tabular}

Perkembangan jumlah mahasiswa IPDN Jatinangor mengalami fluktuatif dalam waktu selama 5 tahun hingga tahun 2016 dan penurunan jumlah mahasiswa terbesar mencapai $-30,46 \%$ yaitu pada tahun 2014. Hal tersebut terjadi karena kebijakan anggaran yang telah ditentukan oleh Kementerian Pendayagunaan Aparatur Negara Dan Reformasi Birokrasi mengenai penerimaan praja di IPDN JatinangorSedangkan untuk perkembangan jumlah anggota perpustakaan cenderung menurun dan mengalami peningkatan di tahun 2016 sebesar $34,47 \%$ dan tetap tidak sebanding dengan idealnya jumlah anggota yang seharusnya sebanding dengan jumlah praja. Perkembangan jumlah anggota aktif dapat dilihat mengalami kenaikan sebesar $11,04 \%$ pada tahun 2012, sedangkan pada tahun 2013, 2014, dan 2015 mengalami penurunan sebesar 16,69\%; 6,30\% dan 6,98\%. Pada tahun 2016 mengalami kenaikan sejalan dengan kenaikan anggota perpustakaan yaitu sebesar $61,67 \%$.

Selain itu, untuk perkembangan jumlah kunjungan mengalami perkembangan yang fluktuatif akan tetapi jumlah kunjungan rata-rata anggota hanya sebagian dari jumlah anggota IPDN Jatinangor. Hal tersebut diduga karena minat pengunjung sebagai anggota yang masih rendah terlihat pada tabel 1.3, perbandingan jumlah anggota dan jumlah anggota yang aktif selama 6 tahun.

Tabel 3.

Perbandingan Jumlah Anggota Perpustakaan dan Jumlah Anggota Aktif di Perpustakaan IPDN

\begin{tabular}{ccccc}
\hline No & Tahun & $\begin{array}{c}\text { Jumlah } \\
\text { Anggota }\end{array}$ & $\begin{array}{c}\text { Jumlah } \\
\text { Anggota } \\
\text { Aktif }\end{array}$ & $\begin{array}{c}\text { Perbandingan } \\
\%\end{array}$ \\
1 & 2011 & 3,125 & 2,219 & 71 \\
2 & 2012 & 3,200 & 2,464 & 77 \\
3 & 2013 & 3,617 & 2,065 & 57 \\
4 & 2014 & 3,226 & 1,935 & 60 \\
5 & 2015 & 2,559 & 1,800 & 70 \\
6 & 2016 & 3,441 & 2,910 & 85 \\
\hline \multicolumn{5}{l}{ Sumber: Data yang diolah }
\end{tabular}

Berdasarkan tabel menunjukan bahwa tidak semua jumlah anggota perpustakaan aktif untuk berkunjung ke perpustakaan IPDN. Rata-rata keaktifan anggota perpustakaan yang merupakan praja hanya $70 \%$ dari jumlah anggota perpustakaan IPDN. Hal tersebut dikarenakan karena minat anggota perpustakaan untuk berkunjung dan menggunakan fasilitas perpustakaan masih rendah.

\section{Rumusan Masalah}

1. Bagaimana pengaruh minat anggota terhadap tingkat kunjungan di Perpustakaan IPDN Jatinangor.

2. Bagaimana pengaruh kualitas pelayanan terhadap tingkat kunjungan di Perpustakaan IPDN Jatinangor.

3. Bagaimana pengaruh minat anggota dan kualitas pelayanan terhadap tingkat kunjungan di Perpustakaan IPDN Jatinangor.

4. Bagaimana upaya manajemen dalam meningkatkan kunjungan ke perpustakaan dengan memperhatikan minat anggota dan kualitas pelayanan di Perpustakaan IPDN Jatinangor.

\section{Maksud dan Tujuan Penelitian}

1. Untuk mengetahui minat anggota terhadap tingkat kunjungan di Perpustakaan IPDN Jatinangor.

2. Untuk mengetahui kualitas pelayanan terhadap tingkat kunjungan di Perpustakaan IPDN Jatinangor.

3. Untuk mengetahui pengaruh minat anggota dan kualitas pelayanan terhadap tingkat kunjungan di Perpustakaan IPDN Jatinangor.

4. Untuk menentukan upaya-upaya manajerial yang perlu dilakukan pada Perpustakaan IPDN Jatinangor berkaitan dengan peningkatan minat anggota dan kualitas pelayanan terhadap tingkat kunjungan di Perpustakaan IPDN Jatinangor.

\section{Kegunaan Penelitian}

Menambah wawasan bagi peneliti mengenai faktor-faktor yang mempengaruhi peningkatan kunjungan anggota ke perpustakaan serta dapat digunakan sebagai bahan acuan bagi peneliti lain untuk membahas lebih jauh tentang faktor-faktor yang mempengaruhi meningkatnya kunjungan anggota ke perpustakaan 
Hasil penelitian ini juga diharapkan dapat digunakan sebagai salah satu dasar pertimbangan dalam pengambilan keputusan dalam bidang perpustakaan IPDN Jatinangor-Sumedang terutama dalam rangka meningkatkan minat dan kualitas pelayanan sehingga jumlah kunjungan meningkat.

\section{TINJAUAN PUSTAKA}

Menurut Yulia (2010:1) pengolaan bahan pustaka merupakan salah satu kegiatan diperpustakaan yang bertujuan untuk melakukan pengaturan bahan pustaka yang tersedia agar dapat disimpan ditempatnya menurut susunan tertentu serta mudah ditemukan dan digunakan oleh pengguna perpustakaan. Secara umum kegiatan pengolahan bahan pustaka diperpustakaan yaiyu; Penginventarisasian, Pemberian Tanda, Pengklasifikasian, Pengkatalogisasian dan Pengolahan Bahan Pustaka.

Menurut Sutarno (2006:20) manajemen perpustakaan adalah pengelolaan perpustakaan yang didasarkan kepada teori dan prinsip - prinsip manajemen. Pendekatan praktik dalam manajemen perpustakaan dapat dilakukan dengan dua cara yaitu melalui Pendekatan Formal dan Pendekatan Informal

Pengertian perpustakaan menurut UndangUndang Republik Indonesia Nomor 43 Tahun 2007 Tentang Perpustakaan menyatakan bahwa: "Perpustakaan adalah institusi pengelola koleksi karya tulis, karya cetak, dan/atau karya rekam secara profesiona 1 dengan sistem yang baku guna memenuhi kebutuhan pendidikan, penelitian, pelestarian, informasi, dan rekreasi para pemustaka."

Slameto (2003: 57) menjelaskan bahwa minat adalah kecenderungan yang tetap untuk memperhatikan dan mengenang beberapa kegiatan. Menurut Slameto (2010:54) menjelaskan bahwa faktor-faktor yang mempengaruhi minat yaitu:

a. Faktor Intern

Faktor jasmaniah seperti kesehatan dan cacat tubuh dan Faktor psikologis seperti : perhatian, tertarik, aktivitas.

b. Faktor Ekstern

Faktor keluarga seperti cara orangtua mendidik, relasi antar anggota keluarga, suasana rumah, keadaan ekonomi keluarga, pengertian orangtua dan latar belakang kebudayaan dan Faktor sekolah seperti metode mengajar, kurikulum, relasi guru dengan siswa, disiplin sekolah, alat pelajaran, keadaan gedung.

\section{Kualitas Pelayanan}

Menurut Kotler (2012:49) mengemukakan bahwa kualitas adalah keseluruhan ciri serta sifat dari suatu produk atau pelayanan yang berpengaruh pada kemampuannya untuk memuaskan kebutuhan yang dinyatakan atau tersirat.

Faktor-faktor yang mempengaruhi kualitas pelayanan menurut Tjiptono (2014) :

- Keandalan (realibility)

- Ketanggapan (responsiveness)

- Keyakinan (Assurance)

- Empati (Empathy)

- Berwujud (Tangibles)

\section{Tingkat Kunjungan}

Tingkat kunjungan adalah tingkat berkunjung atau dapat juga disebut dengan frekuensi berkunjung. Setiap pengguna perpustakaan pasti memiliki frekuensi kunjungan yang berbeda-beda dalam memanfaatkan koleksi dan layanan pepustakaan. Di dalam perpustakaan kunjungan adalah faktor penentu keberhasilan perpustakaan.

\section{Peneliti Terdahulu}

1). Muliaty (2016);

Judul Penelitian: Faktor-Faktor yang Mempengaruhi Kualitas Pelayanan Pada Politeknik Negeri Media Kreatif Makassar. Penelitian ini menyimpulkan bahwa hasil analisis terhadap kualitas pelayanan yang meliputi faktor kehandalan (reliability), Jaminan (assurance), sikap ramah (empaty), serta daya tanggap (responsiveness), yang disetujui responden sebagai faktor yang memiliki kualitas pelayanan dan kehandalan (reliability), Jaminan (assurance), bukti langsung (tangibles), dan daya tanggap (responsiveness), mempengaruhi kualitas pelayanan

\section{2). Nasra Gathoni \& Thomas Van der Walt (2016)}

Judul Penelitian: Evaluating library service quality at the Aga Khan University library: Application

of a total quality management approach. Penelitian ini menyimpulkan bahwa faktor SERVQUAL (bukti langsung (tangibles), kehandalan (reliability) daya tanggap (responsiveness), jaminan (assurance), dan empati (emphaty) ) harus dilakukan penelitian berulang kali untuk memastikan gambaran yang benar dari kualitas pelayanan.

3). Nyoman Oka Dharma, Ni Wayan Sri Budi, I Gede Ngurah Sugata (2013) 
Judul Penelitian: Hubungan Antara Kualitas Layanan Perpustakaan Undiksha Dan Kepuasan Penggunanya

Penelitian ini menunjukan ada hubungan kualitas pelayanan dilihat dari aspek bukti langsung (Tangibles), kehandalan (reliability) daya tanggap (responsiveness), jaminan (assurance), dan empati (emphaty) terhadap kepuasan pengunjung perpustakaan Undiksha.

\section{4). Ketut Gunawan, Sundring Pantja Djati (2011)}

Judul Penelitian: Kualitas Layanan dan Loyalitas Pasien (Studi pada Rumah Sakit Umum Swasta di Kota Singaraja-Bali). Hasil penelitian menunjukkan bahwa Kualitas layanan yang terdiri dari tampilan fisik (tangibles), empati (emphaty), kehandalan (reliability), daya tanggap (responsiveness), jaminan (assurance), dan empati (emphaty) berpengaruh secara parsial terhadap loyalitas pasien.

5). Habir (2015); Judul Penelitian: Pengaruh Layanan Perpustakaan Terhadap Minat Kunjung Pemustaka Di Perpustakaan Stikes Mega Rezky Makassar, hasil Pengaruh layanan perpustakaan terhadap minat kunjung pemustaka di perpustakaan STIKES Mega Rezky Makassar adalah kuat. Dari hasil uji regresi SPSS diperoleh sebesar nilai koefisien korelasi $\mathrm{R}=0,648$, artinya layanan perpustakaan memberikan pengaruh yang kuat terhadap minat kunjung pemustaka.

6). Johan Widjaja, Siana Halim (2014); Judul Penelitian: Faktor - faktor yang Mempengaruhi Minat Berkunjung Mahasiswa ke Perpustakaan Universitas Kristen Petra. Penelitian tersebut menunjukkan bahwa faktor yang memberikan pengaruh adalah faktor library as place dengan nilai pengaruh sebesar 0,75. Faktor yang kurang memberikan pengaruh terhadap minat berkunjung mahasiswa adalah faktor motivasi dosen dengan nilai pengaruh $-0,96$.

\section{Kerangka Pemikiran}

Berdasarkan kajian pustaka dan hasil penelitian sebelumnya yang dilakukan peneliti lain dengan permasalahan yang relevan dalam penelitian ini maka kerangka pemikiran teoritis yang dapat dikembangkan seperti pada gambar 2.1 berikut ini :

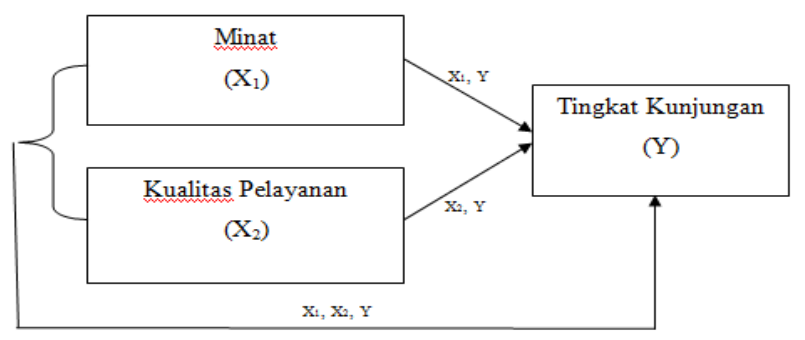

Gambar 1. Analisis Jalur

\section{Hipotesis}

* H1 : Ada pengaruh positif minat terhadap tingkat kunjungan di Perpustakaan IPDN Jatinangor.

* H2 : Ada pengaruh positif kualitas pelayanan terhadap tingkat kunjungan di Perpustakaan IPDN Jatinangor.

* H3 : Ada pengaruh positif minat dan kualitas pelayanan terhadap tingkat kunjungan di Perpustakaan IPDN Jatinangor.

\section{METODE PENELITIAN}

\section{Objek Penelitian}

Objek dalam penelitian ini adalah anggota yang aktif di perpustakaan IPDN Jatinangor yang terdiri dari 3 (tiga ) variabel :

1. Minat, Variabel (X1) sebagai variabel independen

2. Kualitas pelayanan, Variabel (X2) sebagai variabel independen

3. Tingkat kunjungan anggota, variabel (Y) sebagai variabel dependen

\section{Metode Penelitian}

\section{Metode yang Digunakan}

Metode yang digunakan dalam penelitian ini adalah metode deskriptif kuantitatif. Penelitian deskriptif kuantitatif ini bertujuan untuk mendapatkan gambaran serta informasi yang lebih mendalam mengenai sejauh mana minat dan kualitas pelayanan terhadap tingkat kunjungan anggota serta melakukan identifikasi masalah yang dihadapi oleh perpustakaan mengenai cara agar kunjungan anggota ke perpustakaan lebih meningkat. 


\section{Data yang Diperlukan}

Data Primer, adalah data yang diperoleh langsung melalui anggota aktif perpustakaan, dan karyawan perpustakaan dan juga hasil pengamatan langsung di lapangan pada saat melakukan penelitian.

Data Sekunder, adalah data yang diperoleh secara tidak langsung dalam bentuk laporan kegiatan perpustakaan.

\section{Sumber Data}

Data yang diperlukan dan diharapkan dapat memberikan Informasi dalam proses penelitian ini berasal dari : responden, informan, literatur, dan sumber-sumber lain yang memiliki keterkaitan.

\section{Cara Mengumpulkan Data}

Peneliti mengumpulkan data dengan cara sebagai berikut:

1. Observasi

2. Kuisioner

3. Studi Pustaka

\section{Teknik Pengambilan Sampel}

Cara pengambilan sampel dengan accidental sampling, yaitu pengambilan sampel dimana memberikan kuisioner kepada setiap pengunjung anggota perpustakaan yang datang

responden.

Dalam penelitian ini diambil 100

\section{Operasionalisasi Variabel}

Variabel dalam penelitian ini terbagi menjadi dua yaitu variabel bebas dan variabel terikat.

\section{Metode Analisis Data}

\section{Analisis Deskriptif}

Analisis deskriptif digunakan untuk mendeskripsikan persentase masing-masing dari variabel independen yaitu minat $\left(\mathrm{X}_{1}\right)$, kualitas pelayanan $\left(\mathrm{X}_{2}\right)$, serta variabel dependen yaitu tingkat kunjungan $(\mathrm{Y})$.

Metode analisis deskriptif ini menggunakan skala likert. Dikemukakan Sugiyono (2014: 93) bahwa skala Likert digunakan untuk mengukur sikap, pendapat, dan persepsi seseorang atau sekelompok orang tentang fenomena sosial.

Berdasarkan pendapat Sugiyono (2011;93), maka instrument penelitian ini dioleh melalui tabel rekapitulasi skor jawaban untuk jawaban Sangat
Setuju (SS), Setuju (S), kurang setuju (KS) dan tidak setuju (TS).

Data yang digunakan untuk variabel minat anggota (X1), kualitas pelayanan (X2) dan tingkat kunjungan (Y) merupakan data primer yang dikumpulkan melalui kuesioner dan menggunakan skala ordinal. Penulis mulai menggunakan perhitungan dengan menggunakan MSI (Method Succesive Interval) untuk menaikkan skala ordinal menjadi interval. Menurut Syarifudin Hidayat (2005:55) pengertian Method of Successive Interval adalah: "Metode penskalaan untuk menaikan skala pengukuran ordinal ke skala pengukuran interval".

\section{Uji Validitas dan Reabilitas}

1. Validitas

Menurut Sugiyono (2012:121) "hasil penelitian yang valid bila terdapat kesamaan antara data yang terkumpul dengan data yang sesungguhnya terjadi pada objek yang diteliti”.

\section{Reliabilitas}

Menurut Sugiyono (2012:121) “instrumen yang reliabel adalah instrumen yang bila digunakan beberapa kali untuk mengukur obyek yang sama, akan menghasilkan data yang sama.'

Dalam pengujian validitas dan reliabilitas ini menggunakan SPSS (Statistical Product andService Solution)ver 20.

\section{Path Analysis}

Menurut Ridwan (2012:2) model path analysis digunakan untuk menganalisis pola hubungan antar variabel dengan tujuan untuk mengetahui pengaruh langsung maupun pengaruh tidak langsung seperangkat variabel bebas.

\section{Uji Hipotesis}

Uji Parsial (uji t). Menurut Sugiyono (2008:244) uji t pada dasarnya menunjukkan seberapa jauh pengaruh suatu variabel penjelas secara individual alam menerangkan variasi variabel terikat.

Uji Simultan (uji F). Menurut Sugiyono (2008, p264) uji F digunakan untuk menguji variabel - variabel bebas secara bersama-sama terhadap variabel terikat .

\section{Uji Kolerasi}

Menurut Sugiono (2014: 87) metode korelasi adalah metode pertautan atau metode penelitian yang berusaha menghubung-hubungkan antara satu unsur/elemen dengan unsur atau elemen 
lain untuk menciptakan bentuk dan wujud baru yang berbeda dengan sebelumnya. Pengujian ini dilakukan untuk mengetahui hubungan keeratan variabel bebas (X1), (X2), dan Variabel terikat (Y), semakin besar nilai koefesien korelasi semakin erat hubungan variabel bebas dan variabel terikat.

\section{HASIL PENELITIAN DAN PEMBAHASAN}

\section{- Gambaran Umum Perusahaan}

Perpustakaan Institut Pemerintahan Dalam Negeri (IPDN) berdiri sejak bersamaan dengan berdirinya APDN/STPDN. Sesuai dengan perkembangan pendidikan, para pengelola perguruan tinggi termasuk pendidikan tinggi kedinasan menyadari bahwa perpustakaan adalah aset paling utama dalam upaya mengembangkan kehidupan akademis suatu perguruan tinggi.

Sejak tahun 1989 bersamaan dengan berdirinya APDN Nasional, perpustakaan mulai dikelola secara baik. Seiring dengan perubahan status APDN Nasional menjadi Sekolah Tinggi Pemerintahan Dalam negeri (STPDN), perpustakaan di STPDN juga mengalami perkembangan berupa tempat, fasilitas, dana, pengelolaan dan jumlah koleksi baik dalam jumlah judul maupun jumlah eksemplarnya.

Saat ini perpustakaan di lingkungan Institut Pemerintahan Dalam Negeri berada di dua lokasi yaitu di kampus Jatinangor, Kampus IPDN di Cilandak Jakarta, Mataram, Makasar, Manado, Sumatera Barat, Papua, dan Kalimantan Barat.

\section{- Hasil Penelitian}

\section{1) Analisis Deskriptif}

Berdasarkan hasil penelitian dengan menggunakan kuisioner, berikut ini tanggapan responden mengenai minat, kualitas pelayanan dan tingkat kunjungan ke Perpustakaan IPDN Jatinangor :

\section{Persepsi Responden atas Minat}

Berdasarkan hasil kuisioner, kriteria penilaian minat anggota dengan total sebesar 80,09\% termasuk dalam kategori tinggi dikarenakan sesuai kriteria yang telah ditentukan berada pada interval $68,00 \%$ - $83.99 \%$. Minat anggota untuk berkunjung ke Perpustakaan IPDN Jatinangor tidak sangat tinggi dikarenakan faktor eksternal tidak memiliki pengaruh sebesar pengaruh faktor internal yaitu dalam diri dan lingkungan pribadi responden.

\section{Persepsi Responden atas Kualitas Pelayanan}

Berdasarkan hasil kuisioner, kriteria penilaian kualitas pelayanan yang diberikan perpustakaan
IPDN Jatinangor dengan total sebesar $82,76 \%$ dan termasuk dalam kategori baik. Hal tersebut dikarenakan sesuai kriteria yang telah ditentukan berada pada interval $68,00 \%-83.99 \%$.

\section{Persepsi Responden atas Tingkat Kunjungan}

Hasil kuisioner oleh responden mengenai tingkat kunjungan anggota ke Perpustakaan IPDN Jatinangor diperoleh sebesar 81,40\%. Berdasarkan hasil kuisioner, kriteria penilaian tingkat kunjungan yang anggota ke perpustakaan IPDN Jatinangor dengan total sebesar $81,40 \%$ termasuk dalam kategori tinggi. Hal tersebut dikarenakan sesuai kriteria yang telah ditentukan berada pada interval $68,00 \%-83.99 \%$.

\section{2) Uji Validitas dan Reliabilitas}

Uji Validitas

Tabel 4

Korelasi Antar Varaibael

\begin{tabular}{rrrr} 
& \multicolumn{3}{c}{ Korelasi Antar Varaibael } \\
& Y & X1 & X2 \\
Y & 1,000 & 0,473 & 0,715 \\
X1 & 0,473 & 1 & 0,569 \\
X2 & 0,715 & 0,569 & 1
\end{tabular}

Sumber: output SPSS Versi 20

Berdasarkan tabel menunjukkan variabel $\mathrm{Y}$, X1, dan X2 memiliki data yang valid. Hal tersebut dikarenakan $\mathrm{r}$ hitung masing - masing variabel yaitu variabel $\mathrm{Y}$ sebagai tingkat kunjungan, varibel X1 sebagai minat anggota, dan variabel X2 sebagai kualitas pelayanan lebih besar daripada $r$ tabel dua sisi untuk jumlah sampel 100 orang dengan $\alpha=5 \%$ yaitu 0,1966 .

Uji Reliabilitas

Berdasarkan tabel hasil uji reliabilitas menunjukan angka cronbach's alpha sebesar 0,800 dan angka tersebut lebih besar dari pada nilai minimal cronbach's alpha yaitu 0,6. Maka dapat disimpulkan alat ukur dalam penelitian ini reliabilitas.

\section{3) Path Analysis}

Tabel 5

Path Analysis

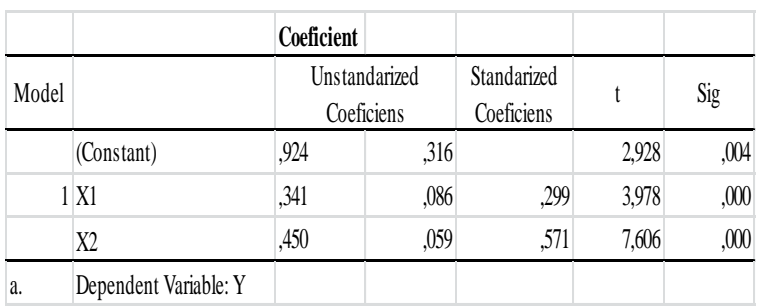

Pada tabel terlihat bahwa koefisien jalur $\mathrm{X}_{1}$ (minat anggota) dan $\mathrm{X}_{2}$ (kualitas pelayanan) 
menjadi 0,299 dan 0,571. Dan kedua variabel adalah signifikan, sedangkan pada tabel 4.15. model summary terlihat nilai $\mathrm{R}$ square sebesar 0,518. Maka koefisien jalur $\varepsilon$ (variabel diluar model) adalah :

$\rho_{y \varepsilon}=\sqrt{ }(1-0,518)=\sqrt{ } 0,482=0,6943$

Maka, diagram jalur yang terbentuk yaitu sebagai berikut :

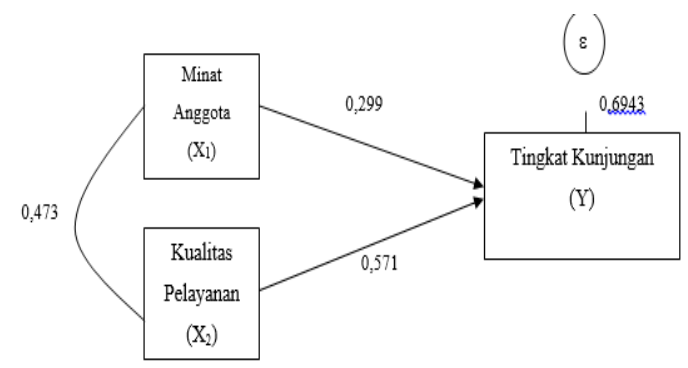

Gambar 2. Diagram Alur

Sumber : Data yang diolah

$Y=P y x X_{1}+$ Pyx $X_{2}+\varepsilon$ Maka,

$Y=0,299 X_{1}+0,571 X_{2+} \varepsilon$

Dimana :

$\mathrm{X}_{1}=$ minat

$\mathrm{X}_{2}=$ kualitas pelayanan

$\mathrm{Y}=$ tingkat kunjungan

Dari persamaan di atas memiliki arti bahwa setiap peningkatan minat anggota sebesar satu satuan, maka akan meningkatkan tingkat kunjungan sebesar 0,299 satuan. Dan setiap peningkatan kualitas pelayanan sebesar satu satuan, maka akan meningkatkan tingkat kunjungan sebesar 0,574 satuan. Dan dapat dilihat nilai koefisien jalur kualitas pelayan lebih besar dibandingan nilai koefisien jalur minat sehingga kualitas pelayanan lebih berpengaruh terhadap tingkat kunjungan daripada minat yang dimiliki anggota.

\section{Uji Hipotesis}

Tabel 6

Uji Parsial (Uji t)

\begin{tabular}{|c|c|c|c|c|c|}
\hline & \multicolumn{2}{|c|}{ Coeficient } & \multirow[b]{2}{*}{$\begin{array}{l}\text { Standarized } \\
\text { Coeficiens }\end{array}$} & \multirow[b]{2}{*}{$t$} & \multirow[b]{2}{*}{ Sig } \\
\hline Model & & & & & \\
\hline (Constant) &, 924 &, 316 & & 2,928 & ,004 \\
\hline $1 \mathrm{Xl}$ &, 341 & 086 & 299 & 3,978 & 000 \\
\hline$X 2$ &, 450 & ,059 & .571 & 7,606 & ,000 \\
\hline
\end{tabular}

a. Dependent Variable: $Y$

Berdasarkan uji t statistik, minat secara parsial berpengaruh terhadap tingkat kunjungan dan kualitas pelayanan secara parsial berpengaruh terhadap tingkat kunjungan dikarenakan nilai sig. $\mathrm{t}$ $=0,000<0,05($ nilai $\alpha)$.

Uji Simultan (Uji F)

Tabel 7

ANOVA

\begin{tabular}{|c|c|c|c|c|c|c|}
\hline Model & Sum of Square & Df & Df & $\begin{array}{l}\text { Mean } \\
\text { Square } \\
\end{array}$ & F & Sig \\
\hline \multirow{3}{*}{1} & Regression & ,675 & 2 & ,338 & $\begin{array}{r}52,12 \\
6\end{array}$ & ,000 \\
\hline & Residual & ,628 & 97 & ,006 & & \\
\hline & Total & 1,303, & 99 & & & \\
\hline
\end{tabular}

a. Dependent Variable: $Y$

b. Predictors: (Constant), X2, X1

Sumber : Output SPSS versi 20

Untuk nilai sig. uji F pada penelitian, kedua variabel minat dan kualitas pelayanan terhadap tingkat kunjungan yaitu sebesar 0,000\%. Dimana, jika Fhitung signifikan pada taraf $<5 \%$, Ha diterima, artinya secara simultan minat dan kualitas pelayanan berpengaruh terhadap tingkat kunjungan.

Tabel 8

Uji Kolerasi

\begin{tabular}{ccccc}
\hline Model & $\mathrm{R}$ & $\begin{array}{c}\mathrm{R} \\
\text { Square }\end{array}$ & $\begin{array}{c}\text { Adjusted } \mathrm{R} \\
\text { Square }\end{array}$ & $\begin{array}{c}\text { Std.Error of } \\
\text { The Estimate }\end{array}$ \\
\hline 1 &, 720 &, 518 &, 508 &, 08047
\end{tabular}

a. Predictors: (Constant), X2,X

Sumber: Output SPSS versi 20

Untuk nilai adjusted R-squared model regresi yaitu sebesar 0,518 atau $51,80 \%$. Hal ini menunjukkan variabel minat anggota dan kualitas pelayanan secara simultan berpengaruh dalam kategori sedang atau cukup berpengaruh terhadap tingkat kunjungan. Dimana berpengaruh sebesar $51,80 \%$.

\section{Hasil Pembahasan}

\section{Pengaruh Minat terhadap Tingkat Kunjungan.}

Hasil kuisioner menunjukan nilai untuk variabel minat anggota yaitu sebesar $82,91 \%$ yang termasuk dalam kategori anggota memiliki minat yang tinggi untuk berkunjung ke perpustakaan. Tingginya minat anggota didukung oleh faktor internal maupun eksternal baik dari dalam diri sendiri, lingkungan keluarga maupun sekolah yang mendorong untuk datang berkunjung ke perpustakaan IPDN Jatinangor.

Terlihat dari hasil uji t statistic dimana nilai $\mathrm{t}$ hitung variabel minat anggota yaitu sebesar 3,978 > dari nilai t tabel sebesar 1,98472 dengan nilai sign. Uji t sebesar $0,000<0,05$. Artinya minat anggota berpengaruh secara parsial terhadap tingkat 
kunjungan di Perpustakaan IPDN. Dimana semakin tinggi minat anggota maka semakin tinggi tingkat kunjungan anggota untuk datang ke perpustakaan IPDN Jatinangor. Hal tersebut sejalan dengan jurnal Johan Widjaja, Siana Halim (2014) yang menyimpulkan adanya pengaruh faktor-faktor minat untuk berkunjung ke perpustakaan.

\section{Pengaruh Kualitas Pelayanan terhadap Tingkat Kunjungan.}

Hasil kuisioner responden memiliki total nilai untuk variabel kualitas pelayanan yaitu $82,76 \%$ dan termasuk pada kategori kualitas pelayanan yang baik.

Terlihat dari hasil uji t statistic dimana nilai $\mathrm{t}$ hitung variabel minat anggota yaitu sebesar 7,606 > dari nilai t tabel sebesar 1,98472 dengan nilai sign. Uji $\mathrm{t}$ sebesar $0,000<0,05$. Artinya kualitas pelayanan berpengaruh secara parsial terhadap tingkat kunjungan di Perpustakaan IPDN. Semakin baik kualitas pelayanan yang dirasakan oleh anggota maka semakin tinggi tingakat kunjungan anggota ke perpustakaan IPDN Jatinangor. Hal tersebut sejalan dengan jurnal Ketut Gunawan, Sundring Pantja Djati (2011) menunjukkan bahwa Kualitas layanan yang terdiri dari tampilan fisik (tangibles), empati (emphaty), kehandalan (reliability), daya tanggap (responsiveness), jaminan (assurance), dan empati (emphaty) berpengaruh secara parsial terhadap loyalitas kunjungan pasien.

\section{Pengaruh Minat dan Kualitas Pelayanan terhadap Tingkat Kunjungan.}

Berdasarkan hasil kuisioner dan observasi langsung ke lapangan, menunjukkan bahwa tingkat kunjungan anggota perpustakaan IPDN jatinangor dikatakan cukup tinggi. Hal tersebut didasarkan hasil kuisioner dimana nilai untuk variabel tingkat kunjungan yaitu $81,40 \%$ termasuk pada kategori tinggi.

Hasil uji F pada penelitian mengambarkan nilai sig. uji f yaitu sebesar $0,000 \%$. Jika Fhitung signifikan memiliki nilai $<5 \%$ atau 0,05 , maka Ho ditolak dan Ha diterima, artinya minat anggota dan kualitas pelayanan berpengaruh secara simultan terhadap tingkat kunjungan. Dan berdasarkan nilai $\mathrm{R}$ squared menunjukkan bahwa pengaruh kedua variabel tersebut berpengaruh sebesar $51,80 \%$.

\section{Tindakan Manajerial}

Berdasarkan latar belakang penelitian, hasil penelitian dan pembahasan penelitian. Dalam hal tingkat kunjungan dikatakan tinggi tetapi dengan frekuensi yang menurun di setiap tahunnya. Yang berarti sudah baik tetapi harus jauh lebih baik dikarenakan idealnya untuk seluruh praja bisa menggunakan fasilitas dan layanan yang disediakan perpustakaan IPDN Jatinangor. Kekurangankekurangan yang dilihat seperti idealnya sebuah ruangan perpustakaan lebih luas disesuaikan dengan jumlah seluruh praja, bukan hanya jumlah anggota saja. Sehingga dengan itu, semoga tingkat kunjungan dapat bertambah baik bagi anggota, non anggota bahkan masyarakat sekitar yang membutuhkan media ilmu pengetahuan.

Dalam hal ini petugas perpustakaan memerlukan penganggaran dasar baik dari peralatan dan perlengkapan penunjang berkembangnya perpustakaan. Diperlukan juga anggaran sumber daya manusia dalam pengelolaan perpustakaan. Hal tersebut dibutuhkan agar optimalisasi pelayanan dapat dilakukan oleh perpustakaan IPDN Jatinangor. Dan penambahan sumber daya manusia pun harus diimbangi dengan pelatihan khususnya pustakawan agar perpustakaan terus berkembang dan berkualitas.

\section{KESIMPULAN DAN SARAN}

\section{- Kesimpulan}

Berdasarkan hasil penelitian yang telah dijelaskan dalam Bab 4, maka dari pada penelitian ini dapat disimpulkan sebagai berikut:

1. Minat anggota berpengaruh secara parsial terhadap tingkat kunjung perpustakaan IPDN Jatinangor. Dimana semakin tinggi minat anggota perpustakaan maka semakin tinggi tingkat kunjungan ke perpustakaan IPDN Jatinangor.

2. Kualitas pelayanan berpengaruh secara parsial terhadap tingkat kunjung perpustakaan IPDN Jatinangor. Dimana semakin baik kualitas pelayanan oleh petugas perpustakaan maka semakin tinggi tingkat kunjungan ke perpustakaan IPDN Jatinangor.

3. Minat anggota dan kualitas pelayanan berpengaruh secara simultan terhadap tingkat kunjung perpustakaan IPDN Jatinangor. Dimana, variabel minat anggota dan kualitas pelayanan memiliki pengaruh sebesar $51,80 \%$ terhadap tingkat kunjungan perpustakaan IPDN Jatinangor.

4. Upaya Manajerial dalam peningkatan kunjungan ke perpustakaan IPDN Jatinangor yaitu membuat anggaran untuk memperluas ruangan agar dapat disesuaikan dengan jumlah praja bukan hanya jumlah anggota perpustakaan. Selain itu, harus didukung dengan jumlah sumber daya manusia yang 
ideal dalam pengelolaan dan pelayanan di perpustakaan IPDN Jatinangor.

\section{- $\quad$ Saran}

Buku-buku dapat dilengkapi lagi baik dengan buku yang lebih up date, lebih lengkap kategorinya, quantity yang lebih banyak serta praja membutuhkan buku kategori diluar pemerintahan akan tetapi buku hiburan yang bersifat positif.

\section{DAFTAR PUSTAKA}

Abdul Rahman Saleh, Rita Komalasari. 2014. Manajemen Perpustakaan. Jakarta : Universitas Terbuka.

Abdul Rahman Saleh.2009. Psikologi; Suatu Pengantar dalam Perspektif Islam. Jakarta: Kencana

Akdon, Riduwan. 2007. Rumus dan Data dalam Aplikasi Statistika. Bandung: Alfabeta.

Ating Somantri dan Sambas Ali Muhidin. 2006. Aplikasi Statistika Dalam Penelitian. Bandung : Pustaka Setia.

Djaali. 2008. Psikologi Pendidikan. Jakarta : PT. Bumi Aksara

Engkos Ridwan Achmad Kuncoro. 2013. Cara Menggunakan dan Memaknai Path Analysis. Alfabeta: Bandung.

Fandy Tjiptono. 2002. Prinsip-Prinsip Total Quality Service. Yogyakarta : Andi.

Ghozali, Imam. 2011. Aplikasi Analisis Multivariate dengan Program IBM SPSS19. Semarang: Badan Penerbit Universitas Diponegoro.

Habir. 2015. Pengaruh layanan perpustakaan terhadap minat kunjung pemustaka di perpustakaan STIKES Mega Rezky Makassar. Jurnal Ilmu Perpustakaan, Informasi,dan Kearsipan Khizanah AlHikmah, 3(2), 156-171.

Johan Widjaja, Siana Halim. 2014. Faktor - faktor yang Mempengaruhi Minat Berkunjung Mahasiswa ke Perpustakaan Universitas Kristen Petra. Jurnal Titra, Vol. 2, No. 1, Januari 2014, pp. 35-40.

Kamus Besar Bahasa Indonesia.

Ketut Gunawan, Sundring Pantja Djati. 2011. "Kualitas Layanan dan Loyalitas Pasien (Studi pada Rumah Sakit Umum Swasta di Kota Singaraja-Bali).”. Jurnal Manajemen
Dan Kewirausahaan, Vol.13, No. 1, Maret 2011: 32-39. Singaraja : Universitas Panji Sakti Singaraja, Universitas Kristen Petra.

Lasa. 2009. Kamus Kepustakawanan Indonesia. Yogyakarta: Pustaka Book Publisher.

Laksana, Fajar. 2008. Manajemen Pemasaran Pendekatan Praktis. Yogyakarta: Graha Ilmu.

Lupiyoadi, Rambat dan Hamdani. 2009. Manajemen Pemasaran Jasa Edisi 2. Jakarta: Salemba Empat.

Moenir. 2001. Manajemen Pelayanan Umum di Indonesia. Jakarta: PT Bumi Aksara.

Mohamad Surya. 2003. Psikologi Konseling, Bandung : Pustaka Bani Quraisy.

Muliaty. 2016. "Faktor-Faktor yang Mempengaruhi Kualitas Pelayanan Pada Politeknik Negeri Media Kreatif Makassar". Jurnal Administrasi Publik, Volume 6, Nomor 1 Tahun 2016, Makasar: Politeknik Negeri Media Kreatif Makassar.

Nasra Gathoni, Thomas Van der Walt. 2016. "Evaluating library service quality at the Aga Khan University library: Application of a total quality management approach". Journal of Librarianship and Information Science1-14. Africa : Aga Khan University, University of South Africa.

Nyoman Oka Dharma, Ni Wayan Sri Budi, I Gede Ngurah Sugata. 2013. "Hubungan Antara Kualitas Layanan Perpustakaan Undiksha Dan Kepuasan Penggunanya". Jurnal Ilmu Sosial dan Humaniora Vol. 2, No. 2, Oktober 2013. Singaraja : UPT. Perpustakaan Universitas Pendidikan Ganesha.

Peraturan Pemerintah No 30 Tahun 1990 Tentang Perguruan Tinggi.

Prasetyo, Bambang. 2008. Metode Penelitian Kuantitatif. Jakarta: PT RajaGrafindo Persada.

Rahayuningsih. 2007. Pengelolaan Perpustakaan. Yogyakarta: Graha Ilmu.

Sedarmayanti dan Syarifudin Hidayat. 2005. Metodologi Penelitian. Bandung : Mandar Maju.

Slameto. 2010. Belajar dan Faktor-faktor yang Mempengaruhinya. Jakarta: Rineka Cipta. 
120 Coopetition, Vol. X, No. 2, November 2019, 111 - 120 e-ISSN 2615-4978

Standar Nasional Perpustakaan Tahun 2011, Perpustakaan Nasional RI.

Standar Nasional Perpustakaan Tahun 2013, Perpustakaan Nasional RI.

Sugiyono. 2010. Metode Penelitian Pendidikan Pendekatan Kuantitatif, Kualitatif, dan $R \& D$. Bandung: Alfabeta.

Sugiyono. 2014. Metode Penelitian Pendidikan Pendekatan Kuantitatif, Kualitatif, dan $R \& D$. Bandung: Alfabeta.

Sukardi. 2003. Metodologi penelitian pendidikan kompetensi dan praktiknya. Jakarta : PT. Raja Grafindo Persada.

Sulistyo-Basuki. 2004. Pengantar Dokumentasi. Bandung: Rekayasa Sains.

Supriyanto. 2006. "Meningkatkan Eksistensi IPI dalam Mengembangkan Profesionalisme Pustakawan". Dalam Supriyanto dan Rimbarawa (Ed.), Aksentuasi Perpustakaan dan Pustakawan. Jakarta:Ikatan Pustakawan Indonesia Pengurus Daerah DKI Jakarta.

Umar, Husein. 2002. Metode Riset Komunikasi Organisasi : sebuah pendekatan kuantitatif, dilengkapi dengan contoh proposal dan hasil riset komunikasi organisasi. Jakarta: PT. Gramedia Pustaka Utama.

Undang - Undang RI No. 20 Tahun 2003 tentang Sistem Pendidikan Nasional.

Undang-Undang RI Nomor 43 Tahun 2007 Tentang Perpustakaan. 